\title{
Recent advances in choledochal cysts
}

\author{
Hiroyuki Tadokoro $^{1 *}$, Masaru Takase ${ }^{2}$ \\ ${ }^{1}$ Department of Gastroenterology, Kasukabe Chuo General Hospital, Saitama, Japan \\ ${ }^{2}$ Division of Pathology, Clinical Laboratory, Koshigaya Municipal Hospital, Saitama, Japan \\ Email: "heroyou27@yahoo.co.jp
}

Received 5 August 2012; revised 18 September 2012; accepted 29 September 2012

\begin{abstract}
Choledochal cysts are a congenital anomaly, and they show dilatation of the intra- or extrahepatic biliary tree. These cysts are uncommon in Western countries, but are not rare in Asian countries. Choledochal cysts are classified into five groups based on location or shape of the cysts. Types I and IV-A cysts are the most common types, which are associated with anomalous pancreaticobiliary junction (APBJ), but other cysts are not associated with APBJ. Types I and IV-A cysts appear to belong to a different category from other cysts embryologically. Types I and IV-A cysts accompany anomalies of the pancreas. Types $I$ and IV-A cysts might occur when left ventral anlage persists, and with disturbed recanalization of the common bile duct. Endoscopic retrograde cholangiopancreatography is the gold standard for detecting APBJ, but it is an invasive procedure. Magnetic resonance cholangiopancreatography (MRCP) is a non-invasive imaging tool for detecting pancreatic and biliary trees. MRCP is the first-choice modality for diagnosing choledochal cysts and APBJ in pediatric patients. Cystoenterostomy is been performed because of high complication and mortality rates. Complete excision of the cysts with Roux-en-Y hepatojejunostomy is a standard procedure for choledochal cysts to prevent postoperative complications, including development of cancer. In this study, we review classification, pathogenesis, diagnosis, and treatment of Types I and IV-A choledochal cysts.
\end{abstract}

Keywords: Choledochal Cysts; Anomalous Pancreaticobiliary Junction; Pancreatic Polypeptide; Ventral Pancreas; Dorsal Pancreas

\section{INTRODUCTION}

Choledochal cysts are congenital anomalies of the biliary tree, and they show dilatation of the intra- and extrahepatic biliary tree. In 1723, Vater first described dilata-

*Corresponding author. tion of the common bile duct [1]. Douglas wrote the first clinical report of choledochal cysts in 1852 [2]. In 1959, Alonso-Lej et al. collected 96 cases of choledochal cysts and classified them into three categories [3]: cystic dilatation of the common bile duct (CBD), diverticula of the CBD, and choledochocele. In 1977, Todani et al. refined this classification by adding two categories [4]. Types I and IV-A cysts are more common in female than in male patients, and the female-to-male ratio ranges from 3:1 to 4:1 [5-7]. The incidence of cysts was reported to be approximately 1:100,000 - 150,000 live births in Western countries [7].

Most of the cysts (85\%) are reported to be diagnosed in the first decade or under 15 years of age. Approximately $20 \%$ of cysts are diagnosed in older patients [8-10]. The risk of gallbladder or bile duct cancer has been reported in many studies. The incidence of biliary tract cancer in patients with choledochal cysts was reported as $6 \%-20 \%$ in the United States and approximately $15 \%$ - 20\% in Japan [11-14]. The incidence of gallbladder or bile duct cancer increases with age. In patients with choledochal cysts under the age of 10 years, the risk of developing biliary duct cancer is $0.7 \%$, and the risk increases to $14.3 \%$ for patients over 20 years of age in Western countries [15]. The incidence of gallbladder or bile duct cancer is $0.3 \%$ in children, whereas it is $15.6 \%$ in adults. Gallbladder or bile duct cancer occurs in $26 \%$ of patients under 40 years old and in $45.5 \%$ of them over 70 years old in the Japanese literature [16]. The incidence of gallbladder cancer (67.8\%) is more frequent than that of bile duct cancer (32.1\%) in patients with choledochal cysts, according to the register of the Japanese Study Group of Pancreaticobiliary Maljunction (JSPBM) [13].

\section{CLASSIFICATION OF CHOLEDOCHAL CYSTS AND ANOMALOUS PANCREATICOBILIARY JUNCTION}

\subsection{Choledochal Cysts}

Todani et al.'s classification of choledochal cysts is as 


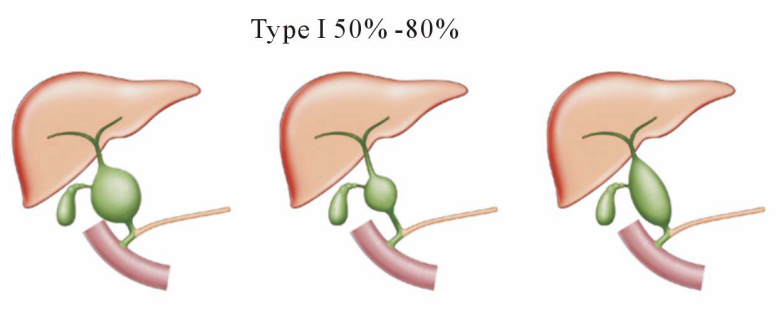

present with segmental cystic dilatations of the intrahepatic bile duct. Caroli's disease is an autosomal recessive disorder, and results from malformation of the embryonic ductal plate at different levels of the biliary tree [25]. This disease results from arrest or derangement in normal embryologic remodeling of ducts and causes varying degrees of destructive inflammation and segmental dilatation [26,27]. Most of Types I and IV cysts are accompanied by an anomalous pancreaticobiliary junction (APBJ). Other cysts are not accompanied by APBJ. Types I and IV cysts should be classified into different categories from other cysts, including diverticulum of the extrahepatic bile duct (Type II), choledochocele (Type III), and Caroli's disease (Type V) embryologically [28,29].

\subsection{APBJ}

APBJ is defined as a junction between the pancreatic and bile ducts and is located outside of the duodenal wall
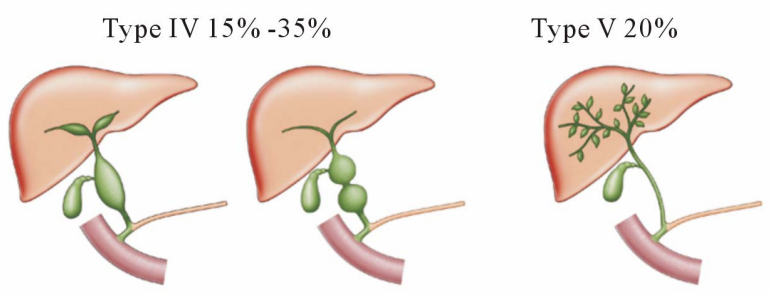

Figure 1. Todani’s classification of choledochal cysts.

follows (Figure 1). Type I cysts consist of saccular or fusiform dilatation of the extrahepatic bile duct. This is the most common type and represents nearly $80 \%-90 \%$ of cases. Type I cysts are further subdivided into type IA (diffuse) cysts, type IB (focal) cysts, and type IC (fusiform) cysts. Subtype IA shows saccular dilatation of the common bile duct. Subtype IB shows focal, segmental dilatation of the common bile duct. Subtype IC has fusiform dilatation of the common hepatic and common bile duct [17]. Type II cysts are a diverticulum of the CBD. Type III cysts are also referred to as choledochoceles, which show dilatation of the intraduodenal portion of the CBD. Choledochoceles are further subdivided into two types as reported by Scholz et al. [18]. Other authors have classified choledochoceles into four or five types $[19,20]$. The pathogenesis of choledochoceles is known, but some authors consider that choledochoceles are a subtype of duodenal duplication [21,22]. Type III cysts or choledochoceles represent $1.4 \%$ to $4.5 \%$ of cases [23]. Type IV cysts show dilatation of either the intra- or extrahepatic bile duct, or both. Type IV cysts can be subdivided into two subtypes: IV-A involving multiple intraand extrahepatic cysts, and IV-B, involving only multiple extrahepatic biliary dilatations. The type IV cyst is the second most common type in adults, and represents $10 \%$ - 15\% of adult cases [24]. Type V cysts (Caroli's disease) of choledochal cysts and account for greater than $90 \%$ of cases [24]. Most of these cysts are complicated by APBJ [31]. In 1969, Babbitt analyzed cholangiograms of patients with choledochal cysts and found that most of them were complicated by APBJ [32]. APBJ is classified according to the types of confluence between the terminal choledochus and pancreatic duct. In 1977, Kimura et al. classified APBJ into two types by analyzing the fusion pattern between the pancreatic and bile ducts. In the P-C type, the main pancreatic duct appears to join the common bile duct, while the common bile duct appears to join the main pancreatic duct in the C-P type [33]. In 1977, Komi et al. classified types of fusion between pancreatic and bile ducts in patients with choledochal cysts into four categories, including type a, type b, type c, and the miscellaneous type [34]. Types a and b correspond to C-P type and P-C type, respectively. In 1991, Komi et al. revised their classification according to the running of the accessory pancreatic duct, and the presence or absence of dilatation of the common channel and the CBD, finally classifying the type of fusion between pancreatic and bile ducts in patients with choledochal cysts into three groups, namely types I, II, and III with their subtypes (Figure 2). Types I, II, and III correspond to the C-P type, P-C type, and complex type, respectively. APBJ is type I in $35.3 \%$, type II in $21.6 \%$, and type III in $43.1 \%$ of cases with choledochal cysts [35].

In 1994, the JSPBM classified APBJ into three subgroups, such as type a (right angle type), type b (acute angle type), and type c (complex type) according to the type of confluence of the main pancreatic duct and the CBD. Type a and type $\mathrm{b}$ correspond to the P-C type and C-P type, respectively. In 2003, Tashiro et al. analyzed 1627 patients who were enrolled by the JSPBM, includ- 
I

a

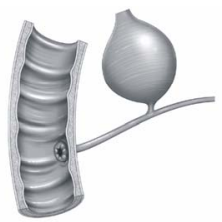

b

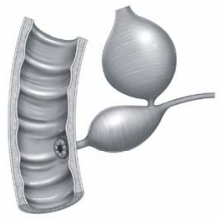

II

a

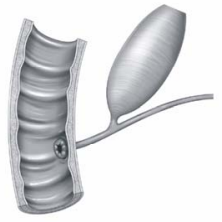

b

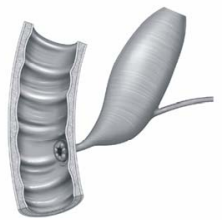

III

a

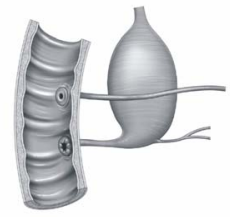

b

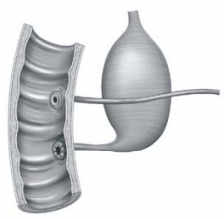

c1

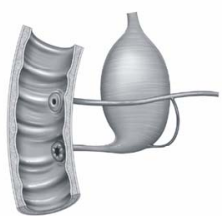

c2

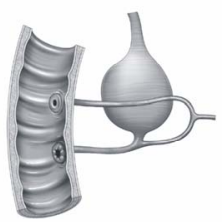

c3

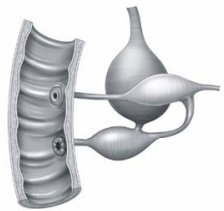

Figure 2. Komi's classification of anomalous union between pancreatic and bile ducts. APBJ were classified into three types according to the angle of this ductal union. In type I, the common bile duct joins the pancreatic duct at a right angle. In type II, the common bile duct joins the pancreatic duct at an acute angle. Both types were subdivided into "a" and "b" according to whether the common channel was dilated or not. In Type III, the common bile duct and the pancreatic ducts formed a complicated network. Type III was subdivided according to Warshow's classification of dominant dorsal pancreatic duct.

ing 1239 patients with choledochal cysts and 388 patients with the non-dilated type of APBJ. APBJ was type a in $57.9 \%$, type b in $32.4 \%$, and type $c$ in $5.6 \%$ of cases with choledochal cysts. APBJ was type b in $60.8 \%$, type a in $29.4 \%$, and type $c$ in $7.2 \%$ cases with the non-dilated type of APBJ [13].

APBJ forms a long common channel, in which pancreatic juice regurgitates into the bile duct. The length of the common channel in patients with APBJ has been previously reported. Nomura et al. reported that the average length of the common channel is $22 \mathrm{~mm}(13-67$ $\mathrm{mm})$ in APBJ, while it is $5 \mathrm{~mm}(2-20 \mathrm{~mm})$ in normal cases in adults [36]. Kimura et al. reported that the average length of the common channel is $28.1 \mathrm{~mm}$ (15 - 46 $\mathrm{mm})$ in APBJ, while it is $4.6 \mathrm{~mm}(2-10 \mathrm{~mm})$ in normal adult controls [37]. The length of the common channel in patients with APBJ overlapped with that in normal cases. Furthermore, the condition in which pancreatic juice regurgitates into the CBD has been reported in patients without APBJ [38]. In this condition, the pancreatic duct connects to the CBD on cholangiopancreatograms, except for when the sphincter of Oddi contracts. Considering these conditions, which are similar to APBJ, APBJ should be defined as when the long common channel presents without any relation to contraction of the sphincter of Oddi.

\section{PRESENTATION}

The classic triad for choledochal cysts is abdominal pain, jaundice, and an abdominal mass. Clinical presentation varies with age, and $80 \%$ of the patients present before the age of 10 years. Children usually have signs and symptoms, but adults are asymptomatic. Eighty-two percent of children present with two or more symptoms, whereas symptoms are found in only $23 \%$ of adult patients [39]. Because children and adults present with different signs and symptoms, the patients can be divided into two groups: an infant group (less than 1 year old), and a classical pediatric or adult group (older than 1 year) [40].

The most common findings in the infant group are jaundice, hepatomegaly, and an abdominal mass, but abdominal pain is not usually evident. Jaundice is found in $64 \%$ of infant patients, and an abdominal mass is found in $82 \%$ of infant patients, but few of the patients present with pancreatitis and cholangitis. The classic triad is present in a minority of infant patients (0\% - 17\%) $[9,39,41,42]$. In pediatric or adult patients, the most common findings are abdominal pain, fever, jaundice and vomiting $[43,44]$. Abdominal pain is the most common symptom in adult patients, with an incidence ranging from $78 \%$ to $90 \%$. Jaundice, nausea, and cholangitis are found in $40 \%-50 \%$ of adult patients. Cholangitis or pancreatitis is a common symptom in adult patients. Dilatation of the bile ducts and stricture cause bile stasis, stone or sludge formation, resulting in ascending cholangitis or pancreatitis [45].

\section{ETIOLOGY}

Etiological theories of choledochal cysts have been proposed by many authors $[46,47]$. In 1935, Yotsuyanagi suggested that choledochal cysts arise from unequal proliferation of the epithelium of the CBD [48]. In 1973, Babbitt considered that choledochal cysts are caused by anomalous pancreaticobiliary junction. Regurgitation of pancreatic juice into the CBD leads to inflammation, epithelial denudation, and weakness of the bile duct wall, eventually leading to cyst formation [49]. In 2001, Matsumoto et al. found that the distal end of the CBD is 
connected to the ducts of the ventral pancreas by analyzing cholangiopancreatograms, and they speculated that APBJ is formed by abnormal fusion between the CBD and ventral pancreatic duct [47].

In 2003, Types I and IV-A choledochal cysts and APBJ without choledochal cysts (non-dilated type of APBJ) were discovered as congenital anatomical anomalies of the pancreas (Figures 3(a)-(c)) [50]. The etiology of Types I and IV-A choledochal cysts has been proposed based on pathological findings. Examination of lobular structure, immunohistochemistry for pancreatic polypeptide (PP), and contours of islets is used to distinguish between the ventral and dorsal pancreas [51-57].

Redundant pancreatic tissue has been found in the head of the pancreas with choledochal cysts. This portion of tissue is composed of a small and compact lobular structure with PP-poor cells (Figure 3(d)). The component of this portion is different from that of the right ventral pancreas or dorsal pancreas. The ventral pancreas is composed of small and tightly packed lobules with PP-rich islets, whereas the dorsal pancreas is composed of larger lobules with PP-poor islets under normal conditions. It is unknown whether this portion of redundant pancreatic tissue is derived from the ventral or dorsal anlage. In chickens and frogs, the left ventral anlage persists, and the two ventral buds fuse together and become part of the mature organ $[58,59]$. Considering the development of other species, such as frogs, chickens and mammals, this redundant pancreatic tissue appears to be derived from the left ventral anlage [29,50]. Choledochal cysts might occur when the left ventral anlage persists and recanalization of the bile ducts is disrupted. Delayed recanalization of the intra- or extra-hepatic bile ducts leads to dilatation of the bile ducts (Figure 4). The shape of the pancreatic head in the non-dilated type of APBJ is different from that of choledochal cysts. Immunohistochemistry of PP has demonstrated that the ventral pancreas is fused to the dorsal pancreas obliquely in the non-dilated type of APBJ [60]. In normal embryonic fusion, the ventral anlage is fused with the dorsal anlage side by side. The ventral anlage is fused to the dorsal anlage in an oblique position in patients with the nondilated type of APBJ, resulting in the developing pancreatic duct fusing with developing bile ducts, forming a long common channel.

Anomalies of the head of the pancreas have been previously reported. In 1970, Stefanini et al. reported that the head of the pancreas presented with an abnormal shape macroscopically at surgery [61]. Li et al. reported an abnormal anatomical location of the major papilla in patients with choledochal cysts. The major papilla was located in the distal portion of the duodenum in approximately $70 \%$ of patients with choledochal cysts [62, 63]. These findings suggested anatomical anomalies of the pancreatic head with choledochal cysts.

\section{DIAGNOSIS}

A preliminary imaging modality for detecting choledochal cysts is ultrasonography, which shows a cystic mass in the right upper quadrant apart from the gallbladder. The sensitivity of ultrasonography for diagnosing choledochal cysts is 71\% - 97\%. Ultrasonography demonstrates that continuity with the bile duct in 93\% in patients [45]. Other modalities, including computed tomo-

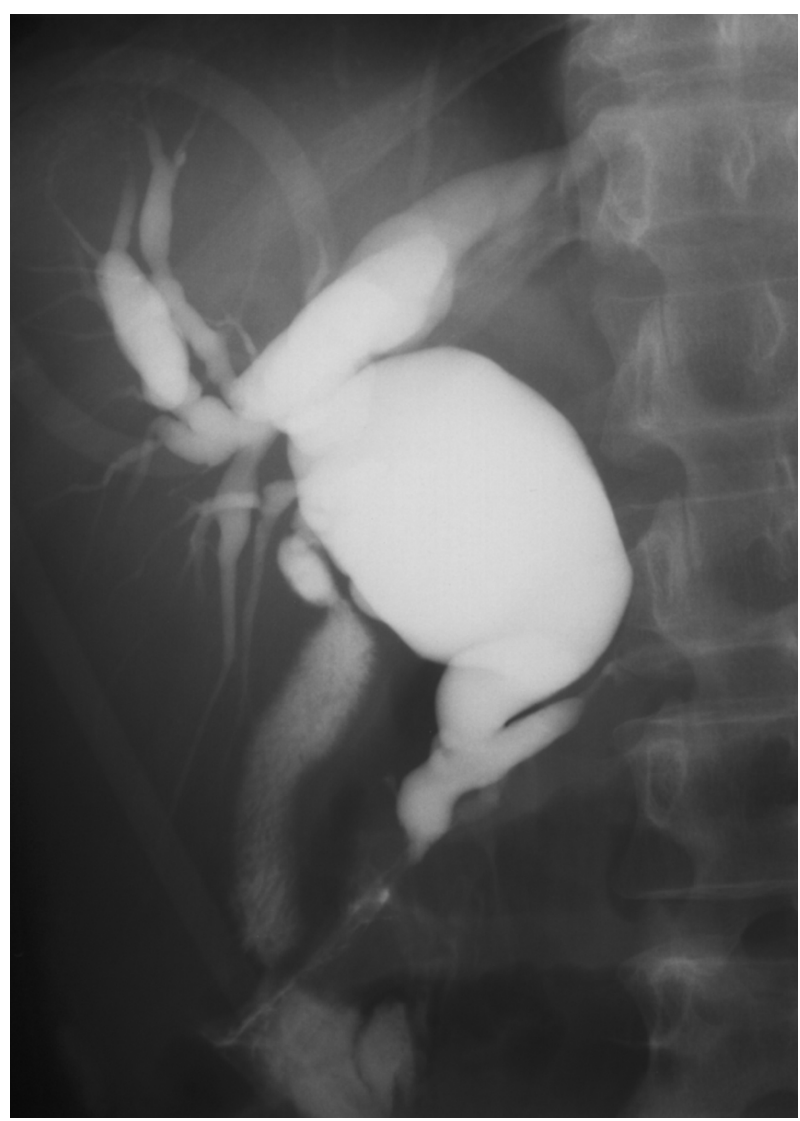

(a)

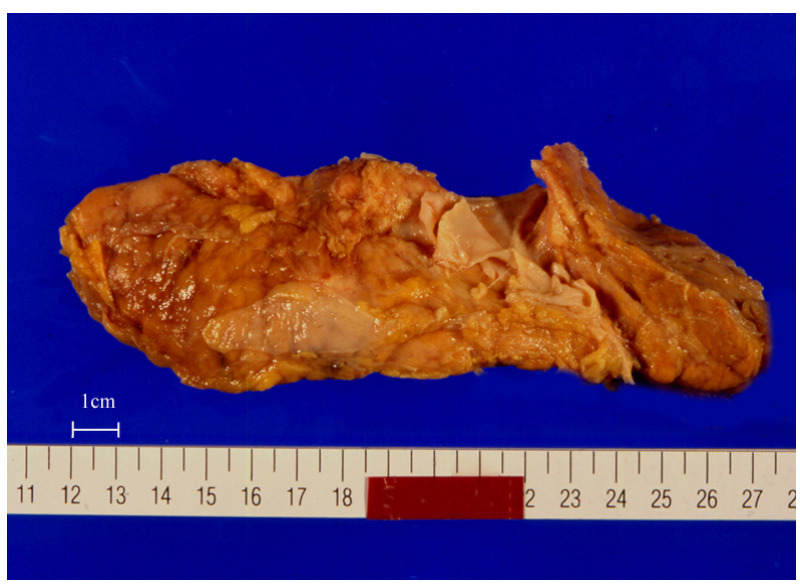

(b) 


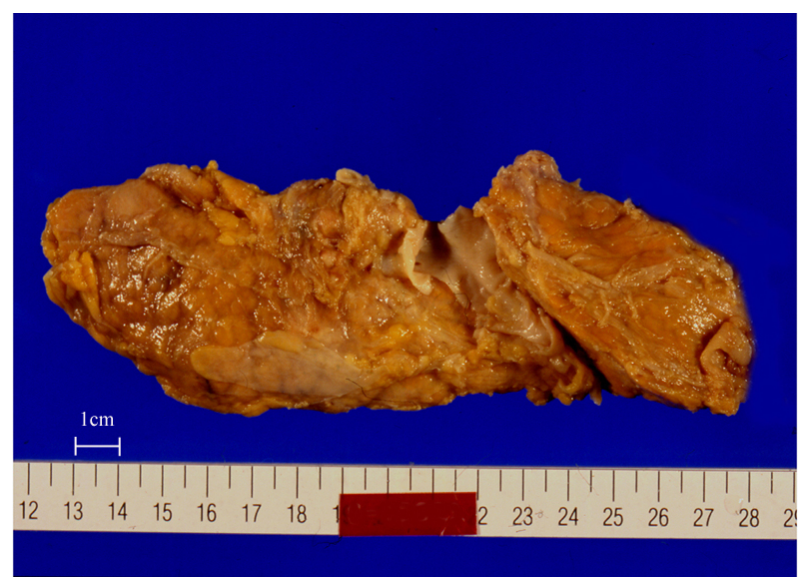

(c)

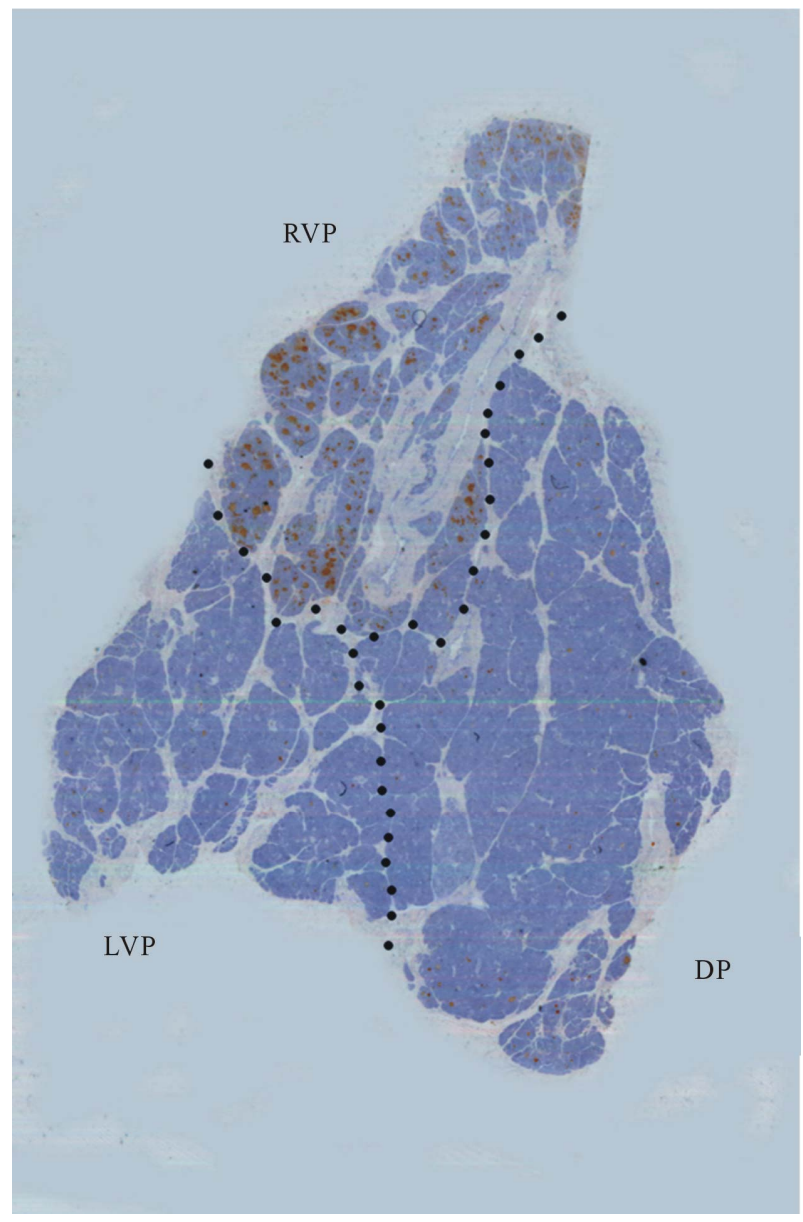

(d)

Figure 3. (a) Type IV-A cysts (a) ERCP showing anomalous pancreaticobiliary junction with dilatation of intra- and extrabiliary ducts; (b), (c) Macroscopic view showing a huge ventral pancreas; (d) Immunohistochemical staining of pancreatic polypeptide (PP). Ventral pancreas was divided into two portions, $\mathrm{PP}$-rich and PP-poor portions. The PP-rich portion was derived from right ventral pancreas (RVP), while the PP-poor portion was derived from left ventral anlage. RVP, right ventral pancreas; LVP, left ventral pancreas; DP, dorsal pancreas. Published with permission of pancreas.
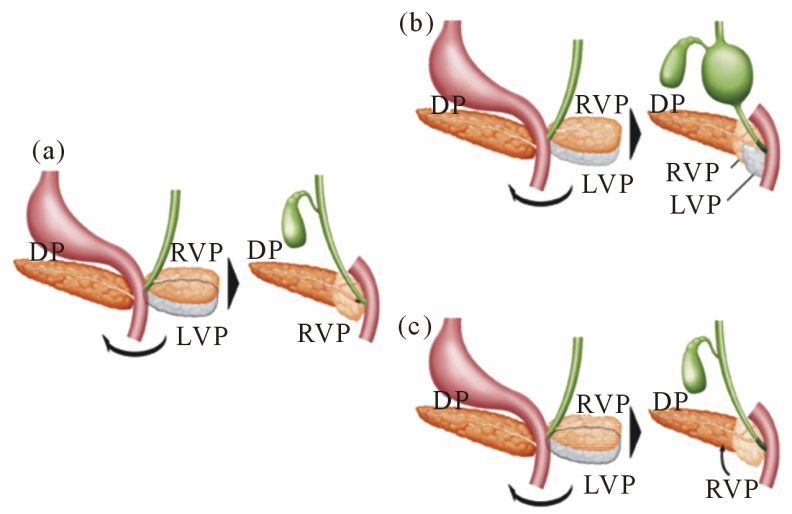

Figure 4. (a) Normal development of the pancreas. The ventral pancreatic anlage is initially paired, with the left lobe subsequently disappearing during development. The ventral pancreatic anlage fuses side by side with the dorsal anlage; (b) Persistence of the left ventral anlage disturbs normal bile duct recanalization, and leads to dilatation of bile ducts; (c) Non dilated-type APBJ occurs when the ventral anlage fuses with the dorsal anlage in an oblique position. RVP, right ventral pancreatic anlage; LVP, left ventral pancreatic anlage; DP, dorsal pancreatic anlage.

graphy (CT), magnetic resonance imaging (MRI) and magnetic resonance cholangiopancreatography (MRCP), are necessary for differentiating other intra-abdominal cysts or demonstrating continuity of the biliary tree.

CT scanning is a useful imaging tool for detecting choledochal cysts, but it is difficult to delineate pancreatic and bile duct union. Multidetector computed tomography (MDCT) allows very thin collimation with a high-quality multiplanar reformation (MPR), which provides detailed information on the pancreatic and bile ducts. In patients with suspected APBJ, MPR images are useful in addition to axial images for detecting an anomalous junction between the pancreatic and bile ducts.

MPR images allow diagnosis of APBJ, with an accuracy of $89 \%$ [64]. Curved planar reformation (CPR) has proved to be a practical and widely used tool for the visualization of curved tubular structures in the human body. CPR may be helpful in depicting pancreatic and common bile ducts $[65,66]$.

CT cholangiography (CTC) is used to evaluate the anatomy and abnormalities of bile ducts [67]. CTC is a useful modality to evaluate aberrant bile ducts before laparoscopic cholecystectomy. This modality can delineate the biliary tree with a sensitivity of $93 \%$. Lam et al. investigated the usefulness of CTC versus MR cholangiography in the diagnosis of choledochal cysts and APBJ. CT cholangiography can depict choledochal cysts with an accuracy of $91 \%$, whereas MR cholangiography visualizes $100 \%$ of the cyst. CTC can visualize APBJ in $64 \%$ of patients, whereas MR cholangiography shows this junction in $46 \%$ of patients [68]. Because nonbreath-hold MR cholangiography is not invasive and 
does not use ionizing radiation and a contrast agent, it is the first-choice modality in pediatric patients with choledochal cysts.

Endoscopic retrograde cholangiopancreatography (ERCP) is the gold standard for diagnosis of APBJ. ERCP is a type of invasive direct cholangiography, which may be associated with significant morbidity and mortality [69]. On the other hand, MRCP is a non-invasive diagnostic imaging for detecting the pancreatic and biliary tree, and it can avoid serious complications associated with ERCP [70]. MRCP has a good accuracy for detecting choledochal cysts. MRCP is able to diagnose choledochal cysts with an accuracy of $82 \%-100 \%$ [68,71,72]. MRCP has difficulty in depicting peripheral bile ducts and small sizes of pancreatic ducts and small duct abnormalities, because of decreased spatial resolution, or a physiological, non-distended state [73]. In general, MRCP has an excellent diagnostic performance for biliary strictures, dilatation, and filling defects larger than $3 \mathrm{~mm}$, but there are diagnostic limitations for filling defects $3 \mathrm{~mm}$ and smaller [74]. The detection rate of MRCP for APBJ in pediatric patients ranges from $40 \%$ to $69.2 \%$ [68,71,75], whereas that in adults ranges from $82 \%$ to $100 \%[72,75]$. The detection rate of MRCP in pediatric patients is much lower than that in adults. MRCP is considered as the first-choice modality for diagnosing choledochal cysts and APBJ in pediatric patients because it is non-invasive and it does not require breath holding.

Hepatobiliary scintigraphy is often used for evaluation of acute cholecystitis and neonatal jaundice [76,77]. It is particularly useful for showing continuity with bile ducts and diagnosis of cyst rupture in patients with choledochal cysts. Hepatobiliary scintigraphy complements other diagnostic tools in the diagnosis of choledochal cysts in pediatric patients [78].

\section{TREATMENT}

The treatment of choice for choledochal cysts is removal of the cysts by surgery. Internal drainage by cystjejunostomy or cystduodenostomy has been performed because of low mortality rates and little technical difficulty $[7,8]$. However, cystoenterostomy without total excision has not been performed, because of complications after surgery, including recurrent cholangitis, intrahepatic calcification, and carcinoma arising from cysts [79-81]. A high incidence of complications after internal drainage has been reported. Chijiiwa and Koga reported complications of cystoenterostomy, including cholangitis in 88\% of patients, choledocholithiasis in $25 \%$ of patients, and hepatolithiasis in 33\% of patients. Seventy percent of these patients required reoperation [80]. Besner et al. reported that patients with choledochal cysts who were treated with either cystduodenostomy or cystjejunostomy still had symptoms in $65 \%$ of them, and a second operation was required in $40 \%$ of patients [82]. Atkinson et al. reported that more than $80 \%$ of patients who had cystoenterostomy performed had recurrent pancreatitis and cholangitis related to residual cysts [10]. Other complications, including stone formation, pancreatitis, portal hypertension, and hepatic abscess after cystoenterostomy or external drainage have been reported. Reoperation was necessary because of intrahepatic stone formation in $58.8 \%$ of patients who had external drainage or cystoenterostomy performed [81].

Cyst remnants lead to malignant transformation of the cyst wall. A surgical procedure without cyst excision does not diminish malignant potential [83]. Postoperative risk without cyst excision has been reported by many surgeons. The risk of postoperative malignancy of internal drainage (30\%) is higher than that of cyst excision (6.1\%). The risk of reoperation of internal drainage (50\%) is higher than that of cyst excision (6.1\%), and the mortality rate is $11 \%$ [84]. Todani et al. reported that cancer developed in $18.6 \%$ of patients who had cystoenterostomy performed approximately 10 years later [11]. The risk of carcinoma in the retained cyst is approximately $50 \%$ in patients treated with cystoenterostomy and is approximately 20 times greater than that in the general population [5]. A revisional operation should be performed in patients previously treated by cystoenterostomy.

Currently, complete excision of a cyst with cholecystectomy and Roux-en-Y hepaticojejunostomy reconstruction (RYHJ) is the standard therapy in Types I and IV-A cysts [39]. The incidence of recurrent cholangitis, intrahepatic calculi, and postoperative stricture has improved significantly with this procedure [85].

The incidence of cholangitis after surgery decreases from $88 \%$ (internal drainage) to $2.3 \%$ - $10.0 \%$ (cyst excision) $[86,87]$. Intrahepatic calculi were observed in $10 \%-16.7 \%$ of pediatric patients who had excision of choledochal cysts $[80,88]$. Postoperative complications, including postoperative cholangitis and intra-hepatic stone formation, are due to anastomotic stricture and/or cholelithiasis in patients with total cyst excision of Types I and IV-A cysts [86]. The reported incidence rate of anastomotic stricture is $4.1 \%$ [89]. A wide anastomosis between the hepatic hilum and intestine may prevent anastomotic stricture.

The incidence of postoperative complications varies with age, surgical procedure, and institutions. The incidence of postoperative complications in children $(9.0 \%)$ is lower than that in adults (42.5\%) [88], and the incidence of postoperative complication varies in institutions, ranging from $2 \%$ to $40 \%$ [90]. Postoperative cholangitis occurs more frequently in Type IV-A cysts than Type I cysts, ranging from $33 \%$ to $44 \%$ [10]. RYHJ has been reported to be successful in $92 \%$ of patients, and the 
complication rate is as low as $7 \%$ compared with that of 33.3\% with hepaticoduodenostomy [91].

Total excision of cysts reduces the risk of cancer development. However, sporadic cancer has been reported a long time after the excision of cysts. Intrahepatic cholangiocarcinoma developing after total resection of choledochal cysts after 10 to 34 years has been previously reported [92-94]. In summary, complete excision of cysts is an adequate standard treatment for Types I and IV-A cysts. Long-term follow-up is necessary to detect the development of carcinoma.

\section{SUMMARY}

We reviewed classification, presentation, etiology, diagnosis, and treatment of Types I and IV-A cysts. Although choledochal cysts are classified based on radiological features, they should be classified considering embryological aspects. Anatomical and pathological findings of choledochal cysts have enabled determination of the etiology of Types I and IV-A cysts. Types I and IV-A cysts occur when the left ventral anlage persists and disturbs normal recanalization of bile ducts, leading to dilatation of intra- or extrahepatic bile ducts. Treatment of choledochal cysts has changed over time because of post-operative complications, especially malignant transformation. Long-term follow-up is necessary to detect cancer.

\section{ACKNOWLEDGMENTS}

The authors thank Yoshihiko Tsuda (Davinchi Medical Illustration Office, Tokyo, Japan) for the artwork in Figures 1, 2 and 4.

\section{REFERENCES}

[1] Vater, A. (1723) Dissertation in auguralis medica. poes diss. qua. Scirrhis viscerum dissert. c. s. ezlerus. Edinburgh: University Library, 70, 19.

[2] Douglas, A. (1852) A case of dilatation of the common bile duct. Journal of Medical Science, 14, 97.

[3] Alonso-Lej, F., Rever, W.B., Jr. and Pessagno, D.J. (1959) Congenital choledochal cyst, with a report of 2, and an analysis of 94, cases. International Abstracts of Surgery, 108, 1-30.

[4] Todani, T., Watanabe, Y., Narusue, M., et al. (1977) Congenital bile duct cysts: Classification, operative procedures, and review of thirty-seven cases including cancer arising from choledochal cyst. The American Journal of Surgery, 134, 263-269. doi:10.1016/0002-9610(77)90359-2

[5] Flanigan, P.D. (1975) Biliary cysts. Annals of Surgery, 182, 635-643. doi:10.1097/00000658-197511000-00017

[6] Yamaguchi, M. (1980) Congenital choledochal cyst. Analysis of 1433 patients in the Japanese literature. The American Journal of Surgery, 140, 653-657. doi:10.1016/0002-9610(80)90051-3
[7] Howard, E.R. (1991) Choledochal cysts. In: Howard, E.R., Ed., Surgery of Liver Disease in Children, Butterworth-Heineman, Oxford, 78-90.

[8] Kasai, M., Asakura, Y. and Taira, Y. (1970) Surgical treatment of choledochal cyst. Annals of Surgery, 172, 844-851. doi:10.1097/00000658-197011000-00009

[9] de Vries, J.S., de Vries, S., Aronson, D.C., et al. (2002) Choledochal cysts: Age of presentation, symptoms, and late complications related to Todani's classification. Journal of Pediatric Surgery, 37, 1568-1573. doi:10.1053/jpsu.2002.36186

[10] Atkinson, H.D., Fischer, C.P., de Jong, C.H., et al. (2003) Choledochal cysts in adults and their complications. $H P B$ (Oxford), 5, 105-110. doi:10.1080/13651820310001144

[11] Todani, T., Watanabe, Y., Toki, A., et al. (1987) Carcinoma related to choledochal cysts with internal drainage operations. Surgery, Gynecology \& Obstetrics, 164, 6164.

[12] Rossi, R.L., Silverman, M.L., Braasch, J.W., et al. (1987) Carcinomas arising in cystic conditions of the bile ducts. A clinical and pathologic study. Annals of Surgery, 205, 377-384. doi:10.1097/00000658-198704000-00006

[13] Tashiro, S., Imaizumi, T., Ohkawa, H., et al. (2003) Pancreaticobiliary maljunction: Retrospective and nationwide survey in Japan. Journal of Hepato-Biliary-Pancreatic Surgery, 10, 345-351. doi:10.1007/s00534-002-0741-7

[14] Edil, B.H., Cameron, J.L., Reddy, S., et al. (2008) Choledochal cyst disease in children and adults: A 30-year single-institution experience. Journal of the American College of Surgeons, 206, 1000-1005; discussion 1005-1008. doi:10.1016/j.jamcollsurg.2007.12.045

[15] Voyles, C.R., Smadja, C., Shands, W.C., et al. (1983) Carcinoma in choledochal cysts. Age-related incidence. Archives of Surgery, 118, 986-988. doi:10.1001/archsurg.1983.01390080088022

[16] Komi, N., Tamura, T., Miyoshi, Y., et al. (1984) Nationwide survey of cases of choledochal cyst. Analysis of coexistent anomalies, complications and surgical treatment in 645 cases. Surgical Gastroenterology, 3, 69-73.

[17] Savader, S.J., Benenati, J.F., Venbrux, A.C., et al. (1991) Choledochal cysts: Classification and cholangiographic appearance. American Journal of Roentgenology, 156, 327-331.

[18] Scholz, F.J., Carrera, G.F. and Larsen, C.R. (1976) The choledochocele: Correlation of radiological, clinical and pathological findings. Radiology, 118, 25-28.

[19] Kagiyama, S., Okazaki, K. and Yamamoto, Y. (1987) Anatomic variants of choledochocele and manometric measurements of pressure in the cele and the orifice zone. The American Journal of Gastroenterology, 82, 641-649.

[20] Sarris, G.E. and Tsang, D. (1989) Choledochocele: Case report, literature review, and a proposed classification. Surgery, 105, 408-414.

[21] Reinus, F.Z. and Weingarten, G. (1976) Choledochocele of the common bile duct. American Journal of Surgery, 132, 646-648. doi:10.1016/0002-9610(76)90363-9

[22] Wearn, F.G. and Wiot, J.F. (1982) Choledochocele: Not a form of choledochal cyst. Canadian Association of Radi- 
ologists, 33, 110-112.

[23] Adamek, H.E., Schilling, D., Weitz, M., et al. (2000) Choledochocele imaged with magnetic resonance cholangiography. The American Journal of Gastroenterology, 95, 1082-1083. doi:10.1016/S0002-9270(99)00926-0

[24] Weyant, M.J., Maluccio, M.A., Bertagnolli, M.M., et al. (1998) Choledochal cysts in adults: A report of two cases and review of the literature. American Journal of Gastroenterology, 93, 2580-2583. doi:10.1016/S0002-9270(98)00514-0

[25] Desmet, V.J. (1992) Congenital diseases of intrahepatic bile ducts: Variations on the theme "ductal plate malformation”. Hepatology, 16, 1069-1083. doi:10.1002/hep.1840160434

[26] Mercadier, M., Chigot, J.P., Clot, J.P., et al. (1984) Caroli’s disease. World Journal of Surgery, 8, 22-29. doi:10.1007/BF01658359

[27] Mortele, K.J., Rocha, T.C., Streeter, J.L., et al. (2006) Multimodality imaging of pancreatic and biliary congenital anomalies. Radiographics, 26, 715-731. doi:10.1148/rg.263055164

[28] Visser, B.C., Suh, I., Way, L.W., et al. (2004) Congenital choledochal cysts in adults. Archives of Surgery, 139, 855-860; discussion 860-852. doi:10.1001/archsurg.139.8.855

[29] Tadokoro, H., Takase, M. and Nobukawa, B. (2011) Development and congenital anomalies of the pancreas. Anatomy Research International, 2011, 351217. doi:10.1155/2011/351217

[30] The Japanese Study Group on Pancreaticobiliary Maljunction (1994) Diagnostic criteria of pancreaticobiliary maljunction Journal of Hepato-Biliary-Pancreatic Surgery, 1, 219-221. doi:10.1007/BF02391070

[31] Miyano, T. and Yamataka, A. (1997) Choledochal cysts. Current Opinion in Pediatrics, 9, 283-288. doi:10.1097/00008480-199706000-00018

[32] Babbitt, D.P. (1969) Congenital choledochal cysts: New etiological concept based on anomalous relationships of the common bile duct and pancreatic bulb. Annales de Radiologie (Paris), 12, 231-240.

[33] Kimura, K., Ohto, M., Ono, T., et al. (1977) Congenital cystic dilatation of the common bile duct: Relationship to anomalous pancreaticobiliary ductal union. American Journal of Roentgenology, 128, 571-577.

[34] Komi, N., Udaka, H., Ikeda, N., et al. (1977) Congenital dilatation of the biliary tract; new classification and study with particular reference to anomalous arrangement of the pancreaticobiliary ducts. Gastroenterologia Japonica, 12, 293-304.

[35] Komi, N., Takehara, H., Kunitomo, K., et al. (1992) Does the type of anomalous arrangement of pancreaticobiliary ducts influence the surgery and prognosis of choledochal cyst? Journal of Pediatric Surgery, 27, 728-731. doi:10.1016/S0022-3468(05)80102-2

[36] Nomura, T., Shirai, Y., Sandoh, N., et al. (2002) Cholangiographic criteria for anomalous union of the pancreatic and biliary ducts. Gastrointestinal Endoscopy, 55, 204208. doi:10.1067/mge.2002.121341
[37] Kimura, K., Ohto, M., Saisho, H., et al. (1985) Association of gallbladder carcinoma and anomalous pancreaticobiliary ductal union. Gastroenterology, 89, 1258-1265.

[38] Kamisawa, T., Amemiya, K., Tu, Y., et al. (2002) Clinical significance of a long common channel. Pancreatology, 2, 122-128. doi:10.1159/000055902

[39] Lipsett, P.A., Pitt, H.A., Colombani, P.M., et al. (1994) Choledochal cyst disease. A changing pattern of presentation. Annals of Surgery, 220, 644-652. doi:10.1097/00000658-199411000-00007

[40] Mishra, A., Pant, N., Chadha, R., et al. (2007) Choledochal cysts in infancy and childhood. Indian Journal of Pediatrics, 74, 937-943. doi:10.1007/s12098-007-0173-0

[41] O’Neill, J.A., Jr. (1992) Choledochal cyst. Current Problems in Surgery, 29, 361-410. doi:10.1016/0011-3840(92)90025-X

[42] Metcalfe, M.S., Wemyss-Holden, S.A. and Maddern, G.J. (2003) Management dilemmas with choledochal cysts. Archives of Surgery, 138, 333-339. doi:10.1001/archsurg.138.3.333

[43] de Vries, J.S., de Vries, S., Aronson, D.C., et al. (2002) Choledochal cysts: Age of presentation, symptoms, and late complications related to Todani's classification. Journal of Pediatric Surgery, 37, 1568-1573. doi:10.1053/jpsu.2002.36186

[44] Buyukyavuz, I., Ekinci, S., Ciftci, A.O., et al. (2003) A retrospective study of choledochal cyst: Clinical presentation, diagnosis and treatment. The Turkish Journal of Pediatrics, 45, 321-325.

[45] Singham, J., Yoshida, E.M. and Scudamore, C.H. (2009) Choledochal cysts: Part 2 of 3: Diagnosis. Canadian Journal of Surgery, 52, 506-511.

[46] Wong, K.C. and Lister, J. (1981) Human fetal development of the hepato-pancreatic duct junction-A possible explanation of congenital dilatation of the biliary tract. Journal of Pediatric Surgery, 16, 139-145. doi:10.1016/S0022-3468(81)80340-5

[47] Matsumoto, Y., Fujii, H., Itakura, J., et al. (2001) Pancreaticobiliary maljunction: Etiologic concepts based on radiologic aspects. Gastrointestinal Endoscopy, 53, 614619. doi:10.1067/mge.2001.113920

[48] Yotsuyanagi S. (1935) Contribution to aetiology and pathology of idiopathic cystic dilatation of the common bile-duct with report of three cases; new aetiological theory based on supposed unequal epithelial proliferation at the stage of the physiological epithelial occlusion of the primitive choledochus. Gann, 30, 601-653.

[49] Babbitt, D.P., Starshak, R.J. and Clemett, A.R. (1973) Choledochal cyst: A concept of etiology. American Journal of Roentgenology, Radium Therapy, and Nuclear Medicine, 119, 57-62.

[50] Tadokoro, H., Suyama, M., Kubokawa, Y., et al. (2003) Persistence of the left part of the ventral pancreas may cause congenital biliary dilatation. Pancreas, 27, 47-51. doi:10.1097/00006676-200307000-00007

[51] Orci, L., Baetens, D., Ravazzola, M., et al. (1976) Pancreatic polypeptide islets and glucagon islets: Distinct topographic distribution in rat pancreas. Comptes Rendus 
Hebdomadaires des Seances de l'Academie des Sciences, Serie D, 283, 1213-1216.

[52] Orci, L., Malaisse-Lagae, F., Baetens, D., et al. (1978) Pancreatic-polypeptide-rich regions in human pancreas. Lancet, 2, 1200-1201. doi:10.1016/S0140-6736(78)92181-5

[53] Paulin, C. and Dubois, P.M. (1978) Immunohistochemical identification and localization of pancreatic polypeptide cells in the pancreas and gastrointestinal tract of the human fetus and adult man. Cell and Tissue Research, 188, 251-257. doi:10.1007/BF00222634

[54] Malaisse-Lagae, F., Orci, L. and Perrelet, A. (1979) Anatomic and hormonal markers for the ventral primordium in the human pancreas? The New England Journal of Medicine, 300, 436. doi:10.1056/NEJM197902223000817

[55] Baetens, D., Malaisse-Lagae, F., Perrelet, A., et al. (1979) Endocrine pancreas: Three-dimensional reconstruction shows two types of islets of langerhans. Science, 206, 13231325. doi:10.1126/science.390711

[56] Gersell, D.J., Gingerich, R.L. and Greider, M.H. (1979) Regional distribution and concentration of pancreatic polypeptide in the human and canine pancreas. Diabetes, 28, 11-15. doi:10.2337/diabetes.28.1.11

[57] Rahier, J., Wallon, J., Gepts, W., et al. (1979) Localization of pancreatic polypeptide cells in a limited lobe of the human neonate pancreas: Remnant of the ventral primordium? Cell and Tissue Research, 200, 359-366. doi:10.1007/BF00234848

[58] Kim, S.K., Hebrok, M. and Melton, D.A. (1997) Pancreas development in the chick embryo. Cold Spring Harbor Symposia on Quantitative Biology, 62, 377-383. doi:10.1101/SQB.1997.062.01.045

[59] Kelly, O.G. and Melton, D.A. (2000) Development of the pancreas in Xenopus laevis. Developmental Dynamics, 218, 615-627. doi:10.1002/1097-0177(2000)9999:9999<::AID-DVDY1 027>3.0.CO;2-8

[60] Tadokoro, H., Takase, M. and Nobukawa, B. (2008) Unusual fusion between ventral and dorsal primordia causes anomalous pancreaticobiliary junction. Pathology International, 58, 498-502.

doi:10.1111/j.1440-1827.2008.02263.x

[61] Stefanini, M., Urbas, J.E. and Crockett, F.L. (1970) Choledochal cyst with associated anomaly of the head of the pancreas. The American Journal of Gastroenterology, 54, 496-499.

[62] Li, L., Yamataka, A., Wang, Y.X., et al. (2001) Ectopic distal location of the papilla of vater in congenital biliary dilatation: Implications for pathogenesis. Journal of Pediatric Surgery, 36, 1617-1622. doi:10.1053/jpsu.2001.27932

[63] Li, L., Yamataka, A., Wang, Y.X., et al. (2003) Anomalous pancreatic duct anatomy, ectopic distal location of the papilla of Vater and congenital biliary dilatation: A new developmental triad? Pediatric Surgery International, 19, 180-185.

[64] Itoh, S., Fukushima, H., Takada, A., et al. (2006) Assessment of anomalous pancreaticobiliary ductal junction with high-resolution multiplanar reformatted images in MDCT. American Journal of Roentgenology, 187, 668675. doi:10.2214/AJR.05.0824

[65] Nino-Murcia, M., Jeffrey, R.B., Jr., Beaulieu, C.F., et al. (2001) Multidetector CT of the pancreas and bile duct system: Value of curved planar reformations. American Journal of Roentgenology, 176, 689-693.

[66] To’o, K.J., Raman, S.S., Yu, N.C., et al. (2005) Pancreatic and peripancreatic diseases mimicking primary pancreatic neoplasia. Radiographics: A Review Publication of the Radiological Society of North America, Inc., 25, 949-965. doi:10.1148/rg.254045167

[67] Sajjad, Z., Oxtoby, J., West, D., et al. (1999) Biliary imaging by spiral CT cholangiography-A retrospective analysis. The British Journal of Radiology, 72, 149-152.

[68] Lam, W.W., Lam, T.P., Saing, H., et al. (1999) MR cholangiography and CT cholangiography of pediatric patients with choledochal cysts. American Journal of Roentgenology, 173, 401-405.

[69] Misra, S.P. and Dwivedi, M. (2002) Complications of endoscopic retrograde cholangiopancreatography and endoscopic sphincterotomy: Diagnosis, management and prevention. The National Medical Journal of India, 15, 2731.

[70] Kaltenthaler, E.C., Walters, S.J., Chilcott, J., et al. (2006) MRCP compared to diagnostic ERCP for diagnosis when biliary obstruction is suspected: A systematic review. BMC Medical Imaging, 6, 9. doi:10.1186/1471-2342-6-9

[71] Miyazaki, T., Yamashita, Y., Tang, Y., et al. (1998) Single-shot MR cholangiopancreatography of neonates, infants, and young children. American Journal of Roentgenology, 170, 33-37.

[72] Sugiyama, M., Baba, M., Atomi, Y., et al. (1998) Diagnosis of anomalous pancreaticobiliary junction: Value of magnetic resonance cholangiopancreatography. Surgery, 123, 391-397. doi:10.1016/S0039-6060(98)70159-X

[73] Vitellas, K.M., Keogan, M.T., Spritzer, C.E., et al. (2000) MR cholangiopancreatography of bile and pancreatic duct abnormalities with emphasis on the single-shot fast spin-echo technique. Radiographics, 20, 939-957; quiz 1107-1108, 1112.

[74] Nandalur, K.R., Hussain, H.K., Weadock, W.J., et al. (2008) Possible biliary disease: Diagnostic performance of high-spatial-resolution isotropic 3D T2-weighted MRCP. Radiology, 249, 883-890. doi:10.1148/radiol.2493080389

[75] Irie, H., Honda, H., Jimi, M., et al. (1998) Value of MR cholangiopancreatography in evaluating choledochal cysts. American Journal of Roentgenology, 171, 1381-1385.

[76] El-Desouki, M., Mohamadiyah, M., Al Rabeeah, A., et al. (1998) Hepatobiliary scintigraphy in the distinction between biliary hypoplasia and biliary atresia. Saudi Journal of Gastroenterology, 4, 8-12.

[77] Indar, A.A. and Beckingham, I.J. (2002) Acute cholecystitis. British Medical Journal, 325, 639-643. doi:10.1136/bmj.325.7365.639

[78] El Desouki, M., Mohamadiyeh, M., Al Rabeaah, A., et al. (1997) Hepatobiliary scintigraphy in the diagnosis of 
choledochal cysts in children. Saudi Journal of Gastroenterology, 3, 78-83.

[79] Olbourne, N.A. (1975) Choledochal cysts. A review of the cystic anomalies of the biliary tree. Annals of the Royal College of Surgeons of England, 56, 26-32.

[80] Chijiiwa, K. and Koga, A. (1993) Surgical management and long-term follow-up of patients with choledochal cysts. American Journal of Surgery, 165, 238-242. doi:10.1016/S0002-9610(05)80518-5

[81] Chaudhary, A., Dhar, P. and Sachdev, A. (1997) Reoperative surgery for choledochal cysts. British Journal of Surgery, 84, 781-784. doi:10.1046/j.1365-2168.1997.02748.x

[82] Besner, G.E., Paddock, H., Nguyen, L., et al. (2008) Surgical treatment. Pediatric Choledochal Cyst Surgery Treatment \& Management. http://emedicine.medscape.com/article/934267-treatment

[83] Mabrut, J.Y., Bozio, G., Hubert, C., et al. (2010) Management of congenital bile duct cysts. Digestive Surgery, 27, 12-18. doi:10.1159/000268109

[84] Ao, K.S., Lu, Y.G., Wang, T., et al. (2002) Procedures for congenital choledochal cysts and curative effect analysis in adults. Hepatobiliary \& Pancreatic Diseases International, 1, 442-445.

[85] Rattner, D.W., Schapiro, R.H. and Warshaw, A.L. (1983) Abnormalities of the pancreatic and biliary ducts in adult patients with choledochal cysts. Archives of Surgery, 118, 1068-1073. doi:10.1001/archsurg.1983.01390090052012

[86] Todani, T., Watanabe, Y., Urushihara, N., et al. (1995) Biliary complications after excisional procedure for choledochal cyst. Journal of Pediatric Surgery, 30, 478-481. doi:10.1016/0022-3468(95)90060-8

[87] Miyano, T., Yamataka, A., Kato, Y., et al. (1996) Hepaticoenterostomy after excision of choledochal cyst in chil- dren: A 30-year experience with 180 cases. Journal of Pediatric Surgery, 31, 1417-1421.

doi:10.1016/S0022-3468(96)90843-X

[88] Yamataka, A., Ohshiro, K., Okada, Y., et al. (1997) Complications after cyst excision with hepaticoenterostomy for choledochal cysts and their surgical management in children versus adults. Journal of Pediatric Surgery, 32, 1097-1102. doi:10.1016/S0022-3468(97)90407-3

[89] Hata, Y., Sasaki, F., Takahashi, H., et al. (1993) Surgical treatment of congenital biliary dilatation associated with pancreaticobiliary maljunction. Surgery, Gynecology \& Obstetrics, 176, 581-587.

[90] Saing, H., Han, H., Chan, K.L., et al. (1997) Early and late results of excision of choledochal cysts. Journal of Pediatric Surgery, 32, 1563-1566. doi:10.1016/S0022-3468(97)90453-X

[91] Shimotakahara, A., Yamataka, A., Yanai, T., et al. (2005) Roux-en-Y hepaticojejunostomy or hepaticoduodenostomy for biliary reconstruction during the surgical treatment of choledochal cyst: Which is better? Pediatric Surgery International, 21, 5-7. doi:10.1007/s00383-004-1252-1

[92] Ono, S., Sakai, K., Kimura, O., et al. (2008) Development of bile duct cancer in a 26-year-old man after resection of infantile choledochal cyst. Journal of Pediatric Surgery, 43, E17-19. doi:10.1016/j.jpedsurg.2008.01.073

[93] Shimamura, K., Kurosaki, I., Sato, D., et al. (2009) Intrahepatic cholangiocarcinoma arising 34 years after excision of a type IV-A congenital choledochal cyst: Report of a case. Surgery Today, 39, 247-251. doi:10.1007/s00595-008-3825-4

[94] Goto, N., Yasuda, I., Uematsu, T., et al. (2001) Intrahepatic cholangiocarcinoma arising 10 years after the excision of congenital extrahepatic biliary dilation. Journal of Gastroenterology, 36, 856-862. doi:10.1007/s005350170010 